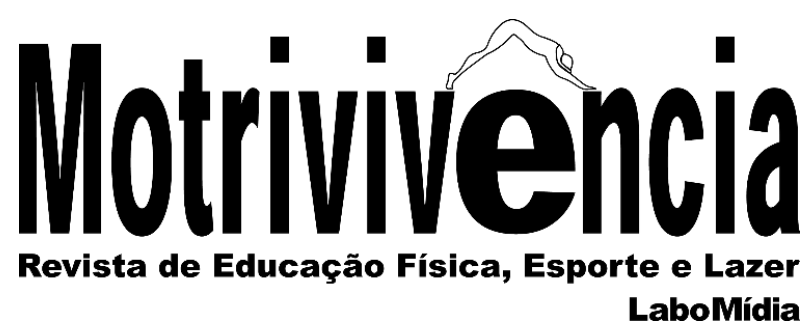

\title{
Os elementos que marcam as especificidades na formação de professores de Educação Física
}

\section{RESUMO}

O presente estudo objetivou analisar as especificidades na formação do professor de Educação Física na perspectiva de quatro grupos compostos por profissionais que estão à frente das principais discussões no que tange essa área. Este estudo é de cunho qualitativo e do tipo pesquisa descritivaanalítica. A amostra foi composta por 20 profissionais de Educação Física. Os resultados mostraram que a perspectiva geral dos participantes indica que nos cursos de licenciatura em Educação Física são trabalhados os conhecimentos relacionados à cultura corporal, as políticas educacionais, aos conhecimentos didático-pedagógicos, bem como, todo o contexto do ensino formal. Conclui-se que a formação do licenciado em Educação Física possui características próprias, e ter clareza das suas particularidades é importante, pois $o$ não conhecimento dessas especificidades pode acarretar situações preocupantes como, por exemplo, a falta de uma base teórico-prática consistente e de um objeto de estudo que norteie o trabalho pedagógico dos professores.

PALAVRAS-CHAVE: Educação física; Legislação; Formação de professor
Andreia Cristina Metzner

Doutora em Ciências da Motricidade (UNESP/Rio Claro)

Centro Universitário UNIFAFIBE

Bebedouro, São Paulo, Brasil acmetzner@hotmail.com

${ }^{\circ}$ http://orcid.org/0000-0002-8403-3824

Alexandre Janotta Drigo

Doutor em Educação Física (FEF/UNICAMP)

Programa de Pós-graduação em Ciências da Motricidade da Universidade Estadual Paulista "Júlio de Mesquita Filho" - UNESP - Campus de Rio Claro, Rio Claro, São Paulo, Brasil alexandredrigo@hotmail.com

(ㄴ) http://orcid.org/0000-0001-8744-1914 


\title{
The elements that mark the specificities in the formation of Physical Education teachers
}

\begin{abstract}
The purpose of the article was to analyze the specificities in the formation of Physical Education teachers in the perspective the four political groups that represent to discussions in this area. This is a qualitative descriptive-analytic study. Participants comprised 20 Physical Education professionals. According to the general perspectives of the participants indicate that the teacher education is knowledge related to corporal culture, educational politics, the didactic-pedagogical knowledge, and all the formal education. It is concluded that the formation of Physical Education teachers has specifics characteristics, and knowing these particulars is important, because the unfamiliarity of these characteristics can cause worrying situations, for example, the lack of a solid theoreticalpractice basis and an object of study that guides the pedagogical work of teachers.
\end{abstract}

KEYWORDS: Physical education; Legislation; Teacher education

\section{Los elementos que marcan las especificidades en la formación de profesores de Educación Física}

\section{RESUMEN}

El presente estudio tuvo como objetivo analizar las especificidades en la formación de profesores de Educación Física desde la perspectiva de cuatro grupos compuestos por profesionales que están a la vanguardia de las principales discusiones en esta área. Este estudio es cualitativo y descriptivoanalítico. La muestra estuvo conformada por 20 profesionales de Educación Física. Los resultados mostraron que la perspectiva general de los participantes indica que en los cursos de Educación Física, se trabaja el conocimiento relacionado con la cultura corporal, las políticas educativas, el conocimiento didáctico-pedagógico, así como todo el contexto de la educación formal. Se concluye que la formación del licenciado em Educación Física tiene sus propias características, y es importante tener claras sus particularidades, porque la falta de conocimiento de estas especificidades puede causar situaciones preocupantes, por ejemplo, la falta de una base teóricopráctica consistente y un objeto de estudio que guía el trabajo pedagógico de los docentes.

PALABRAS-CLAVE: Educación física; Legislación; Formación del profesor 


\section{INTRODUÇÃO}

Os cursos de formação em nível superior possuem objetivos específicos visando formar profissionais habilitados para atuar em diferentes áreas. Para Oliveira (2011) “a formação inicial é entendida como processo de apropriação sistemática da cultura profissional” (p.88). Núñez e Ramalho (2009) reconhecem que a formação inicial é um processo estruturado e orientado para o desenvolvimento profissional, além disso, todo esse processo acontece em espaços formais de ensino e são norteados por objetivos e exigências atuais, bem como, pelas perspectivas e especificidades da profissão.

Assim, os cursos de licenciatura têm como foco a formação de professores. Para tal, estes necessitam proporcionar aos alunos/futuros docentes uma base de conhecimentos e experiências que os possibilitem intervir no ensino formal.

O Art. $3^{\circ}$ da Resolução n. ${ }^{o}$ 02/2015 explicita que os cursos de formação inicial de professores têm como propósito:

A preparação de profissionais para funções de magistério na educação básica em suas etapas - educação infantil, ensino fundamental, ensino médio - e modalidades - educação de jovens e adultos, educação especial, educação profisssional e técnica de nível médio, educação escolar indígena, educação do campo, educação escolar quilombola e educação a distância - a partir de compreensão ampla e contextualizada de educação e educação escolar (BRASIL, 2015, p.03).

Nesse contexto, os cursos de licenciatura formam professores, bem como, os habilitam e os qualificam para atuarem nas diferentes etapas e modalidades da Educação Básica.

É na formação inicial e no exercício da docência que os professores irão se apropriar do habitus da profissão, ou seja, dos modos de ser e de agir dos docentes.

$\mathrm{Na}$ teoria de Bourdieu, o conceito de habitus é trazido pelo autor para explicar as relações existentes entre as estruturas objetivas e subjetivas, ou seja, entre as regras determinadas pela organização social em que o agente está inserido e as formas de pensamentos e ações dos indivíduos. No caso do habitus, esse termo é utilizado para conceituar as estruturas subjetivas, portanto, a forma como cada pessoa entende, interpreta e age sobre o mundo ao seu redor (BOURDIEU, 1983). Para Nogueira e Nogueira (2017) ele é “a ponte, a mediação, entre as dimensões objetiva e subjetiva do mundo social” (p.24).

Isso significa que as nossas ações não são meros produtos do acaso, mas sim, possuem uma ligação direta com o habitus que é o princípio gerador das práticas a partir da interiorização de determinados valores, normas e regras que norteiam o contexto social e que, em um momento posterior, também operará nesse contexto. Ou seja, cada sujeito vivencia uma série de experiências 
no campo social em que está inserido e essas experiências estruturam internamente a sua subjetividade orientando as suas ações (NOGUEIRA e NOGUEIRA, 2017).

Com base nesses princípios, acreditamos que ao longo da formação inicial o aluno/futuro professor incorporará um conjunto de valores, atitudes, concepções teóricas etc., que irão orientar o seu trabalho na escola, juntamente, com as especificidades e exigências encontradas no exercício profissional.

Nesse sentido, as novas exigências legais, sociais e do mundo do trabalho ocasionam mudanças e adequações no âmbito do Ensino Superior e, por conseguinte, novos habitus serão formados. No que concerne especificamente à formação em Educação Física, Honorato (2017) exemplifica essas mudanças ao trazer à tona os diferentes modelos formativos, como o mecanicista e o esportivista, que acarretaram ao longo dos anos alterações na forma de atuação desses profissionais, uma vez que esses modelos priorizavam determinados conteúdos e apresentavam determinadas formas de ensinar. Por isso, para a referida autora, a formação de professores de Educação Física é um processo em permanente construção e transformação, e essas modificações se dão frente às demandas institucionais e as perspectivas da sociedade.

A nosso ver, além dessas demandas ou imbricados a elas, temos as determinações legislativas que influenciam de forma direta as estruturas dos cursos, propostas curriculares e parâmetros didático-pedagógicos que ocasionam transformações na formação inicial dos professores.

Dentre as determinações legislativas e propostas curriculares, consideramos a Lei n. ${ }^{0} 9.696$ de 1998 (Regulamentação da Profissão) e as Resoluções n. 01 e n. ${ }^{\circ} 02$ de 2002 (Diretrizes Curriculares Nacionais para a Formação de Professores da Educação Básica) como as mais expressivas e as que tiveram maior impacto na área de Educação Física (BRASIL, 1998; BRASIL, 2002a; BRASIL, 2002b). Impacto observado na organização de grupos específicos mediante ou consequentes a essas legislações: um grupo que se tornou declaradamente contrário a essas transformações de natureza científica apresentando discurso adverso à regulamentação da Educação Física e a existência do bacharelado, e um grupo formado a partir do sistema de regulamentação profissional que emerge como força política. Esses dois grupos formam uma força antagônica com influência tanto na formação como nas definições de campo de trabalho da Educação Física, e somam-se a outros dois grupos de influência que entendemos como gestores de cursos e pesquisadores na área de formação profissional. Esses grupos corroboram com as análises de Drigo et al. (2020) sobre as forças políticas que tensionam a Educação Física. 
Destarte, este estudo, objetivou analisar as especificidades de formação do professor de Educação Física na perspectiva de quatro grupos compostos por profissionais que estão à frente das principais discussões no que tange essa área.

\section{CAMINHOS METODOLÓGICOS DA PESQUISA}

\section{Caracterização do Estudo}

Este estudo tem como base os pressupostos da abordagem qualitativa (MINAYO, 2009) e o método utilizado foi a pesquisa descritiva-analítica. $\mathrm{O}$ método descritivo tem como características “observar, registrar, analisar, descrever e correlacionar fatos ou fenômenos sem manipulá-los, procurando descobrir com precisão a frequência em que um fenômeno ocorre e sua relação com outros fatores" (MATTOS, ROSSETO JÚNIOR e BLECHER, 2004, p.15). Já as pesquisas analíticas contemplam o estudo aprofundado das informações coletadas com o intuito de explicar e contextualizar um fenômeno (THOMAS e NELSON, 1996). Assim, a presente pesquisa buscou realizar, a partir da conexão desses dois métodos, um estudo detalhado envolvendo coleta de dados, análise e interpretação dos mesmos.

\section{Participantes}

Para alcançar os nossos objetivos buscou-se encontrar dentro da Educação Física os representantes de grupos que possuem poder e voz dentro da área de formação de professores.

Os participantes foram selecionados de forma intencional, ou seja, optamos por uma amostra não probabilística (GIL, 2008). Assim, a escolha dos sujeitos da pesquisa realizou-se por meio do interesse na opinião específica de pessoas que fazem parte de quatro grupos relacionados à Educação Física e que tem representatividade social, política e científica nesse setor, conforme descrito anteriormente.

Nesse sentido, fizeram parte da amostra os profissionais de Educação Física que ocupam cargos em Entidade Científica com atuação nacional e que discursavam publicamente contrário às legislações sobre profissão, lutando em defesa da licenciatura ampliada; Coordenadores de Cursos de Licenciatura em Educação Física de Instituições Públicas (uma Federal e três Estaduais); Profissionais atuantes no Sistema de Regulamentação Profissional; e Pesquisadores que estudam formação profissional em Educação Física.

Os critérios que levaram a estas escolhas pautaram-se no fato que a Entidade Científica e o Sistema de Regulamentação Profissional são grupos concorrentes dentro da Educação Física (DRIGO et al., 2020), os Pesquisadores selecionados tem como foco o estudo e a pesquisa sobre a 
formação inicial nessa área, e o grupo de Coordenadores de Cursos de Licenciatura possui atribuições políticas, gerenciais e acadêmicas em instituições de grande renome.

Participaram do estudo 20 sujeitos, sendo cinco representantes de cada um dos grupos mencionados anteriormente, conforme o quadro abaixo:

\begin{tabular}{|c|c|c|}
\hline GRUPOS & PARTICIPANTES & SIGLA ADOTADA \\
\hline \multirow{5}{*}{$\begin{array}{c}\text { GRUPO A - Entidade Científica com } \\
\text { Atuação Nacional }\end{array}$} & 1 & $\mathrm{~A} 1$ \\
\hline & 2 & $\mathrm{~A} 2$ \\
\hline & 3 & A3 \\
\hline & 4 & $\mathrm{~A} 4$ \\
\hline & 5 & A5 \\
\hline \multirow{5}{*}{$\begin{array}{l}\text { GRUPO B - Coordenação de Curso de } \\
\text { Licenciatura em Educação Física }\end{array}$} & 6 & $\mathrm{~B} 1$ \\
\hline & 7 & $\mathrm{~B} 2$ \\
\hline & 8 & B3 \\
\hline & 9 & B4 \\
\hline & 10 & B5 \\
\hline \multirow{5}{*}{$\begin{array}{c}\text { GRUPO C - Sistema de Regulamentação } \\
\text { Profissional }\end{array}$} & 11 & $\mathrm{C} 1$ \\
\hline & 12 & $\mathrm{C} 2$ \\
\hline & 13 & $\mathrm{C} 3$ \\
\hline & 14 & $\mathrm{C} 4$ \\
\hline & 15 & $\mathrm{C} 5$ \\
\hline \multirow{5}{*}{$\begin{array}{c}\text { GRUPO D - Pesquisadores que estudam } \\
\text { Formação Profissional em } \\
\text { Educação Física }\end{array}$} & 16 & D1 \\
\hline & 17 & $\mathrm{D} 2$ \\
\hline & 18 & D3 \\
\hline & 19 & D4 \\
\hline & 20 & D5 \\
\hline
\end{tabular}

Fonte: Elaboração Própria

\section{Instrumentos de Coleta de Dados}

O Projeto foi submetido ao Comitê de Ética do Instituto de Biociências de Rio Claro/Universidade Estadual Paulista (UNESP), e após a sua aprovação, por meio do Parecer $n^{\circ}{ }^{\circ}$ 1.658.702 (CAAE: 56771116.5.0000.5465), iniciamos os procedimentos de coleta de dados.

Os instrumentos de coleta de dados são "técnicas empregadas, pelo pesquisador, para coletar, medir e/ou avaliar os dados buscados diretamente em suas fontes ou de maneira empírica" (MATTOS, ROSSETO JÚNIOR e BLECHER, 2004, p.90). Para a realização deste estudo a técnica empregada foi a entrevista semiestruturada.

A entrevista semiestruturada envolve a elaboração prévia de algumas perguntas podendo, no decorrer da entrevista, acrescentar outros temas ou questões importantes para a pesquisa. É uma 
forma de poder explorar mais amplamente uma questão e obter informações complementares ao foco do trabalho (ANDRADE, 2006).

O roteiro de entrevista foi elaborado e, posteriormente, validado. Após a validação do roteiro, iniciamos a coleta de dados. As entrevistas foram realizadas ao longo do ano de 2017. O tema central das questões foi as Diretrizes Curriculares Nacionais para a formação dos professores de Educação Física e este foi desmembrado em outros eixos temáticos, dentre eles as especificidades dessa formação inicial.

\section{Análise dos Dados}

Em termos metodológicos, no tratamento dos dados, optamos pelo procedimento denominado análise de conteúdo temática. A análise temática, proposta por Minayo (1993), tem como foco a identificação de temas relevantes num corpo de informações.

\section{RESULTADOS E DISCUSSÃO}

A especificidade da escola "consiste na socialização do saber sistematizado" (SAVIANI, 2015, p.288). Esse saber sistematizado caracteriza-se como o conhecimento "formalmente construído e reconstruído a partir do processo histórico e social do acúmulo da produção e do desenvolvimento histórico da humanidade" (OLIVEIRA, 2011, p.29). Portanto, não se trata de qualquer tipo de saber, mas sim, do conhecimento elaborado, sistematizado e pertencente à cultura erudita (SAVIANI, 2015).

Por conseguinte, cada área de conhecimento possui suas particularidades no que se refere ao trato dos conhecimentos específicos no contexto escolar. Desse modo, de acordo com Correia (2016), é fundamental "que cada área ou docente tenha a compreensão da sua especificidade de forma a se situar no diálogo curricular" (p.834).

No caso da Educação Física, o seu desenvolvimento no âmbito escolar é permeado por algumas especificidades. Para Moura e Antunes (2014) a sua especificidade é o movimento, e as Diretrizes n. ${ }^{\circ} 07$ de 2004 corroboram com essa ideia ao afirmar que o objeto de estudo e aplicação da Educação Física é o movimento humano (BRASIL, 2004). Já para Oliveira (2011) e Taffarel et al. (2006) o objeto de conhecimento e estudo da Educação Física é a cultura corporal e, portanto, a sua especificidade localiza-se precisamente no âmbito dessa cultura corporal que abrange diferentes práticas corporais elaboradas ao longo da história da humanidade, cujos significados foram sendo construídos nos múltiplos contextos socioculturais (AYOUB, 2001). 
Assim, de acordo com os autores supramencionados, podemos dizer que o conhecimento específico da Educação Física se fundamenta no movimento humano e nas suas diversas manifestações (tais como os jogos, brincadeiras, danças, esportes, ginásticas etc.) contextualizadas socioculturalmente e estudadas no âmbito das diferentes ciências. Porém, identificar um núcleo fundador ou a essência da Educação Física não é tarefa fácil devido ao reconhecimento da pluralidade do campo, no entanto, é possível levantarmos alguns indícios sobre as especificidades na formação dos professores a partir dos apontamentos feitos por nossos entrevistados.

Verificamos que os grupos pesquisados (GRUPO A - Entidade Científica com Atuação Nacional; GRUPO B - Coordenação de Curso de Licenciatura em Educação Física; GRUPO C Sistema de Regulamentação Profissional; GRUPO D - Pesquisadores que estudam Formação Profissional em Educação Física) destacaram, principalmente, que nos cursos de licenciatura em Educação Física são trabalhados os conhecimentos relacionados à cultura corporal, as políticas educacionais, aos conhecimentos didático-pedagógicos, bem como, todo o contexto do ensino formal (alunos, projeto político-pedagógico, comunidade escolar, relação professor-aluno etc.).

No quadro abaixo (QUADRO 2) foram destacadas as ideias centrais dos depoimentos de cada participante:

Quadro 2: Relato dos participantes sobre as especificidades dos cursos de licenciatura

\begin{tabular}{|c|l|}
\hline \multicolumn{1}{|l|}{ GRUPO A - ENTIDADE CIENTÍFICA COM ATUAÇÃO NACIONAL } \\
\hline Participantes & \multicolumn{1}{c|}{ Ideias } \\
\hline A1 & •Conhecimento sobre a cultura corporal. \\
\hline A 2 & $\bullet$ Trabalhar a cultura de movimento. \\
\hline A3 & $\bullet$ Conhecer a política educacional brasileira. \\
\hline A 5 & •Formar professores. \\
\hline GRUPO B - COORDENAÇÃO DE CURSO DE LICENCIATURA EM EDUCAÇÃO FÍSICA
\end{tabular}




\begin{tabular}{|c|c|}
\hline & $\begin{array}{l}\text { - Entender sobre educação, políticas educacionais, projeto pedagógico. } \\
\text { - Conhecimentos pertencentes ao núcleo comum da Educação Física }\end{array}$ \\
\hline \multicolumn{2}{|c|}{$\begin{array}{l}\text { GRUPO D - PESQUISADORES QUE ESTUDAM FORMAÇÃO } \\
\text { EDUCAÇÃO FÍSICA }\end{array}$} \\
\hline Participantes & Ideias \\
\hline D1 & - Trabalhar com a escolarização. \\
\hline D2 & $\begin{array}{l}\text { - Trabalhar na escola. } \\
\text { - Entender os anseios e capacidades no outro indivíduo. }\end{array}$ \\
\hline D3 & $\begin{array}{l}\text { - Professor que ensina Educação Física na escola. } \\
\text { - Precisa entender de educação, aluno etc. }\end{array}$ \\
\hline D4 & $\begin{array}{l}\text { - Corpo de conhecimentos que abrange: conhecimentos pedagógicos, do conteúdo } \\
\text { específico e do contexto no qual atua. }\end{array}$ \\
\hline D5 & $\begin{array}{l}\text { - Compreender a educação escolarizada, o trabalho docente. } \\
\text { - Cultura corporal. }\end{array}$ \\
\hline
\end{tabular}

Fonte: Elaboração Própria

Para ilustrar esses apontamentos selecionamos trechos das entrevistas de cada grupo pesquisado:

"Eu acho que cada área tem as suas especificidades que estão relacionadas com a própria área, com o próprio conhecimento que é produzido nessa área. Uma especificidade da Educação Física é a questão de trabalhar com a cultura de movimento. Então, o profissional da Educação Física deve ser apto a trabalhar criticamente com esse determinado conteúdo" (Participante A2).

"Tanto o bacharelado quanto a licenciatura, ambos os cursos tem uma preocupação com a formação do campo profissional, então, eles formam profissionais. A diferença está na ênfase do processo justamente pedagógico e didático e da absorção que, a meu ver, está na progressão desse conhecimento pedagógico dos conteúdos que o curso de licenciatura faz, que forma o professor partindo do principio que ele vai ter a especificidade do ensino dentro do conceito de escola, em um espaço que também tem um conteúdo específico, mais escolarizado" (Participante B4).

"A especificidade principal é que a Educação Física escolar deve estar alinhada com os objetivos da educação. Então, a formação do docente em Educação Física tem que estar alinhada com a formação do cidadão autônomo e preparar para o mundo do trabalho. Ele tem que dar conta disso. A formação tem que instrumentalizá-lo para agir dessa forma. Segundo aspecto, eu não sei se chamo de inter ou multidisciplinaridade, o trabalho em equipe dentro da escola. (...) Outra especificidade, eu tenho que entender educação, ou seja, antes de entender Educação Física eu tenho que entender educação, antes de entender Educação Física eu tenho que entender politicas educacionais, antes de entender Educação Física eu tenho que entender de projeto pedagógico, antes do projeto pedagógico eu tenho que entender da escola, meu planeta é escola e não podemos esquecer isso" (Participante C5).

"Porque no fundo é o seguinte, isso está lá, eu vou usar um nome melhor mas isso já está tudo lá, você tem que conhecer a matéria que você ensina, você tem que ter um conhecimento pedagógico, você tem que ter um conhecimento pedagógico do conteúdo especifico, ou seja, como eu transformo tudo isso, eu tenho que saber dar aula do meio para o fim e do fim para o começo, eu tenho que conhecer os meus 
alunos, eu tenho que conhecer o contexto como qual eu trabalho. Essas questões elas são básicas. Então, a formação ela se assenta nisso dai"” (Participante D4).

Em relação aos destaques feitos pelos grupos participantes da pesquisa, especificamente sobre a cultura corporal ser uma das especificidades do trabalho de Educação Física, Taffarel et al. (2006) afirmam que a Educação Física caracteriza-se pelo trabalho pedagógico e pela docência no esfera da cultura corporal. Por isso, é necessário considerarmos que a base da formação acadêmica e do trabalho do professor é a estruturação da atividade pedagógica e o trato com o conhecimento da cultura corporal. Logo, para os autores:

A docência, entendida como trabalho pedagógico, é, portanto, a identidade profissional do professor de Educação Física. Isto pode ser verificado pelos fatos quando nos reportamos à atividade profissional e identificamos seu sentido, significados, finalidades, meios e métodos ao longo da história. Caracteriza-se, também, por tratar de um campo de conhecimento que se estrutura a partir das práticas históricas, socialmente produzidas, cientificamente estudadas e investigadas e, criativamente, ensinadas de geração a geração, referentes à cultura corporal (TAFFAREL et al., 2006, p.161).

Gallardo (2003) ratifica que a especificidade da Educação Física são os conteúdos da cultura corporal, por isso, os cursos de licenciatura devem formar profissionais capazes de compreender, analisar, sistematizar e aplicar qualquer atividade e/ou elemento pertencente a essa respectiva cultura.

O termo cultura corporal tornou-se presente nas discussões da área de Educação Física a partir de meados do século XX (GRAMORELLI, 2014). No entanto, apesar de estar bastante disseminada no meio acadêmico e em vários documentos legais, essa expressão é pouco compreendida no meio profissional da Educação Física e, além disso, "têm assumido diferentes conotações, provenientes das distintas interpretações feitas por diversos autores, muitas vezes fundamentadas em concepções diferentes e até divergentes" (NEIRA e NUNES, 2006, p.209).

Não temos aqui o intento de aprofundar essa discussão a respeito da cultura corporal, no entanto, apresentaremos alguns pontos relevantes sobre essa terminologia visto que a mesma se destacou em diversos momentos nas falas de nossos entrevistados.

Ao discutir a cultura corporal a partir da sua gênese, Gramorelli (2014) mostra, em seu estudo, que esse termo surgiu no início da década de 80, em um período em que os pressupostos biológicos e o desenvolvimento de habilidades motoras estavam muito presentes no contexto da Educação Física, por isso, essa terminologia foi mencionada com clareza somente em um ensaio escrito em 1987 por Valter Bracht. A autora também expõe que em textos oficiais, o termo cultura corporal foi utilizado pela primeira vez, em 1989, em uma proposta curricular do Estado de Pernambuco. 
A cultura corporal emergiu, de acordo com Neira e Gramorelli (2015), "num contexto sóciopolítico bastante específico, numa conjuntura de crítica à esportivização hegemônica na Educação Física brasileira" (p.4). Nessa época, buscava-se uma Educação Física mais humana e que tivesse como eixo central a cultura corporal da população brasileira (SOUZA JÚNIOR et al., 2011).

Em 1992, foi publicada a obra intitulada "Metodologia do Ensino de Educação Física", também conhecida popularmente como Coletivo de Autores. Nesse livro, a cultura corporal é entendida como:

O acervo de formas de representação do mundo que o homem tem produzido no decorrer da história, exteriorizadas pela expressão corporal: jogos, danças, lutas, exercícios ginásticos, esporte, malabarismo, contorcionismo, mímica e outros, que podem ser identificados como formas de representação simbólica de realidades vividas pelo homem, historicamente criadas e culturalmente desenvolvidas (SOARES et al., 1992, p.38).

Para Gramorelli (2014) a obra supracitada é uma referência importante para a área de Educação Física, pois algumas pesquisas constataram que esse livro é um dos mais referenciados em editais de concursos públicos para professores de Educação Física em vários Estados e regiões brasileiras. Souza Júnior et al. (2011) a consideram um clássico da área e uma leitura essencial para aqueles que trabalham com a Educação Física escolar, além de continuar sendo uma das bases centrais para os cursos de formação inicial e continuada.

Na opinião de Neira e Nunes (2006), além de pontuar a cultura corporal como objetivo de estudo da Educação Física, o livro do Coletivo de Autores, também tornou visível a necessidade de contextualizar os fatos e retomar os processos históricos durante a construção do conhecimento. Esse questionamento sobre os reais objetivos e meios adotados pela Educação Física e pela educação escolar fez com que a cultura corporal fosse incorporada como uma forma de atribuir outra visão a essa disciplina, demonstrando que as aulas estavam além da fixação e execução de gestos técnicos e melhoria da aptidão física. Ou seja, "a Educação Física passou a situar as práticas corporais no contexto social mais amplo, entendendo-as como suportes onde se fixavam os signos da classe social em que foram criadas e recriadas" (p.6).

Souza Júnior et al. (2011) complementam que a cultura corporal expressa na obra em foco apregoa a ideia de que as práticas corporais estão inseridas em um contexto social e histórico, onde o ser humano confere um sentido particular à essas práticas ao mesmo tempo em que é embutido de um significado e valor atribuídos socialmente. Nas palavras dos autores, "a cultura corporal se configura dimensão constituinte da produção cultural humana, condicionada histórica e socialmente" (p.408). 
Posteriormente, no final da década de 90, a cultura corporal permeou outros documentos de abrangência nacional como, por exemplo, os Parâmetros Curriculares Nacionais (PCN). A inserção desse termo nos PCN expressa uma nova visão para a área de Educação Física, onde há uma preocupação em compreender "as práticas corporais como elementos da própria cultura" (GRAMORELLI, 2014, p.55).

Nos dias atuais, o termo cultura corporal está presente em diversos documentos e propostas de cunho educacional como, por exemplo na Base Nacional Comum Curricular (BNCC), e também compõe outras configurações influenciadas por novas teorias que ampliam a discussão em torno dessa temática. Dentre essas novas significações atribuídas a esse conceito são "acrescidas as noções de discurso e identidade, concretizadas no entendimento de cultura como campo de lutas atravessado por relações de poder que atuam na validação de determinados significados em detrimento de outros" (NEIRA e GRAMORELLI, 2015, p.12).

Nesse caso, as mudanças nos status e nos significados das práticas corporais são geradas a partir dos embates entre os grupos e as esferas da sociedade. Para exemplificar, Neira e Gramorelli (2015) apresentam as seguintes situações:

Em certo contexto, uma modalidade esportiva pode ser produzida discursivamente como feminina e, em outro, vista como masculina (é o caso do futebol no Brasil e nos Estados Unidos); uma dança popular pode ser desterritorializada e, em seguida, apropriada por membros da elite (tome-se como exemplo, o forró universitário) e, finalmente, uma luta tida como prática marginal e desprestigiada num momento, pode, em outra época, ter seu sentido relacionado a um grande espetáculo (a transição experimentada pelo UFC é uma boa ilustração do fato). Nas situações mencionadas o que definiu uma posição ou outra não foi algo próprio, específico da prática corporal em tela, mas sim o resultado de ações e discursos que legitimaram o significado que interessava aos grupos mais poderosos (p.12).

Portanto, compreender a cultura corporal como resultado de disputas entre setores e grupos sociais faz com que nas aulas de Educação Física seja adotada atividades de ensino e situações didáticas que proporcionem a identificação das forças em atuação e dos interessados, bem como, dos discursos e posicionamentos adversos com relação à prática corporal. Pois, nesse jogo das relações de poder, é importante que os alunos compreendam que a cultura corporal está inserida em uma cultura mais ampla que é gerada pela disputa dos grupos que a coabitam (NEIRA e GRAMORELLI, 2015).

Após essas abreviadas considerações sobre a cultura corporal, nós trataremos das demais especificidades da formação dos licenciados em Educação Física apontadas pelos participantes dessa pesquisa. Porém, antes de iniciarmos essa discussão é importante destacar que no decorrer da análise dos dados encontrados, ficou evidente a polissemia conceitual que impera no campo 
(movimento humano, cultura corporal e cultura de movimento), marcando as suas diferentes apropriações teóricas, por exemplo, o termo movimento humano foi utilizado pelo participante C4, Cultura Corporal por A1 e D5, e Cultura de Movimento pelo entrevistado A2. Essa questão não será aprofundada nesse momento por não ser o foco desse estudo, mas, acreditamos ser necessário o desenvolvimento de debates mais amplos sobre esses conceitos no campo da Educação Física.

Ao seguirmos com a análise notamos, por meio dos depoimentos dos grupos entrevistados, que os conhecimentos a respeito da legislação, propostas e contextos educacionais também permeiam a especificidade dos cursos de licenciatura. Para Correia (2016) a Educação Física escolar é um subsistema do sistema educacional e, portanto, ela possui uma relação direta com a própria organização, finalidades e princípios da educação brasileira. Nesse sentido, o autor considera que para atingir a eficácia desse subsistema, a Educação Física necessita "ser mediada e reavaliada na sua interação com a especificidade da educação escolarizada, pois essa é premissa da sua inserção nesse contexto" (p.833).

Se a Educação Física faz parte de um sistema maior que é o sistema escolar brasileiro, "então, a especificidade da formação do licenciado deve permear essas coisas: a educação, políticas educacionais, a escola, projeto político pedagógico e logicamente a Educação Física como parte de 50\% do curso", conforme relata o Participante C5.

Outra questão evidenciada nas entrevistas, que diz respeito à interação com os conhecimentos da educação escolarizada, refere-se à forma como a Educação Física seleciona, sistematiza e problematiza os seus conteúdos no contexto escolar. Esse ponto é descrito pelo Participante D5:

"E aí nós vamos para mais um outro nivel, aprofundando verticalmente, que é a
especificidade da docência em Educação Física para entender que uma coisa é a
cultura corporal no lato senso, na dinâmica da sociedade como um todo, e por ela
ser um aspecto da realidade relevante na vida das sociedades e nas vidas
individuais, ela é merecedora de ser um objeto da escolarização. (...) eles passam
por um processo de transformação didático-pedagógica, há uma diferença da
dança não escolar e a dança escolar, ou a ginástica escolar e a ginástica não
escolar, da cultura corporal de movimento escolar e a não escolar, e quando ela
adentra ela é fruto de uma escolha intencional, grávidas de interesses e leituras
parciais, circunstanciais, perspectivais”.

Correia (2016) corrobora com o posicionamento do Participante D5 ao afirmar que os conteúdos de ensino da Educação Física ao adentrar na escola devem ser estruturados e assumir formas diferenciadas para atender as intenções educativas que compõem os programas e currículos escolares. Do ponto de vista do autor, "todos os conteúdos que justificam as disciplinas escolares 
existem inicialmente fora da instituição escolar (cultura) e, quando adentram, recebem um incremento didático e metodológico (cultura escolar)” (p.833).

Em outras palavras, os esportes, as danças, as brincadeiras e as demais práticas corporais trabalhadas dentro da escola diferem das mesmas atividades ministradas fora do domínio escolar, e é essa diferenciação e diálogo com a educação escolarizada que embasa a formação e a atuação do licenciado em Educação Física.

Além das especificidades destacadas anteriormente, dois participantes (B1 e B5) ressaltaram que a Educação Física é um componente curricular diferenciado, pois utiliza espaços distintos da sala de aula tradicional e tem como principal característica ser experiencial:

"Embora a Educação Física seja um componente curricular em tese como outro qualquer na escola a gente sabe que na prática não é, é totalmente diferente, usa espaços diferentes, é visto de maneira diferente, existe uma ideia por parte de quem não é da área o que é a Educação Física que necessariamente não é o que é a Educação Física. (...) A Educação Física está exposta, literalmente, porque está todo mundo olhando, se intrometendo às vezes, interrompendo a aula para fazer outras atividades porque aquele é um horário que a criança está ali atoa, então, eu posso utilizar esse horário” (Participante B1).

"O que a gente tem observado infelizmente é que os alunos tem aula em sala de aula e perde, provavelmente, a peculiaridade principal da Educação Física. Então, eu penso que ser professor de Educação Física é hoje entender que a Educação Física não pode perder a sua principal característica que é ser vivencial, ser experiencial e, logicamente, estudar as questões e as demandas que envolvem os seus grandes temas, os seus grandes eixos, de uma forma bastante crítica porque são temas muito abrangentes que estão relacionados ai com todo o projeto de desenvolvimento do País, de desenvolvimento das pessoas, de desenvolvimento da educação" (Participante B5).

Por se tratar de uma disciplina que tem como objetivo de estudo a cultura corporal, o espaço utilizado para a realização das aulas e as formas como essas práticas corporais são trabalhadas diferem substancialmente de outros componentes curriculares como, por exemplo, Português e Matemática que tem a sala de aula como local de trabalho.

Campos (2004) reforça que a Educação Física é marcada pela sua especificidade que é o trabalho com o corpo e movimento, por isso, possui características peculiares. Para Salgado (2017) ao trabalhar com a cultura corporal os professores de Educação Física precisam de espaços e materiais diferenciados para desenvolverem as suas aulas.

Assim, ao direcionarmos o nosso olhar para a Educação Física escolar percebemos que a organização dessa disciplina possui as particularidades anteriormente citadas e que, portanto, torna- 
se necessário inserir essas questões no âmbito da formação inicial dos professores para que ela não perca "a sua principal característica que é ser vivencial, ser experiencial” (Participante B5). Além disso, deve-se ter ciência de que "embora a Educação Física seja um componente curricular em tese como outro qualquer na escola a gente sabe que na prática não é, é totalmente diferente, usa espaços diferentes, é visto de maneira diferente" (Participante B1).

Por isso, em muitas instituições de ensino, a Educação Física é concebida, por exemplo, como um apêndice curricular, é lembrada em apenas eventos festivos e esportivos, e os locais aonde acontecem as aulas (quadra, pátio, ginásio etc.) não são privativos coincidindo com espaços destinados ao recreio ou a passagem de pessoas (SALGADO, 2017).

Nesse contexto, ressalta a autora que:

É necessário um salto qualitativo sobre as concepções e os conceitos básicos de Educação Física Escolar no sentido, de disseminar o conhecimento sobre a cultura corporal. Quando me refiro a conceitos básicos de Educação Física, considero numa perspectiva antropológica que o corpo carrega as marcas culturais da sociedade em que está inserido e que ao desenvolver qualquer processo pedagógico, temos que considerar este aspecto para pensar o movimento humano (SALGADO, 2017, p.64).

Concordamos com os entrevistados que a disciplina de Educação Física utiliza de recursos e espaços diferenciados, como quadra, sala de lutas, bolas e arcos, tal como outros componentes necessitam de laboratório, ateliê, entre outros. Entretanto, esse "espaço diferenciado" não é exclusividade dessa área.

Por fim, a Educação Física é um componente curricular obrigatório da Educação Básica e deve estar integrada à proposta pedagógica da escola. Portanto, mesmo sendo um componente diferenciado e possuindo certas especificidades, conforme foi descrito pelos participantes da pesquisa, "o seu desempenho enquanto disciplina formativa, passa pelo mesmo crivo educacional que as outras disciplinas" (COSTA, 2004, p.24).

Isso significa que a formação do licenciado em Educação Física possui algumas características próprias, e ter clareza das suas particularidades é importante, pois o não conhecimento dessas especificidades pode acarretar situações preocupantes como, por exemplo, a falta de uma base teórico-prática consistente e de um objeto de estudo que norteie o trabalho pedagógico dos professores, resultando na formação de docentes despreparados para atuarem no contexto escolar, bem como, na ausência ou na não mobilização dos saberes necessários para atuação nesse campo profissional. 


\section{CONSIDERAÇÕES FINAIS}

O estudo priorizou a perspectiva de quatro grupos relacionados à Educação Física e que tem representatividade social, política e científica nesse setor. Em relação ao objetivo da pesquisa que foi analisar as especificidades de formação do professor de Educação Física, não encontramos divergências nas opiniões dos entrevistados. Dessa forma, mesmo sendo colaboradores de segmentos distintos e demonstrando posicionamentos críticos em relação às transformações legislativas na área de formação inicial de professores, estes apresentaram considerações que coadunam com os outros grupos.

Ao tratarmos da especificidade de um curso, estamos buscando um traço comum que o caracterize e o identifique perante os demais. Destarte, a análise dos depoimentos dos profissionais participantes da pesquisa mostrou que o que confere especificidade à Educação Física são: a cultura corporal, o contexto e as políticas educacionais, o fato de ser vivencial e de utilizar espaços diferenciados para a prática pedagógica.

Por isso, os cursos de licenciatura necessitam promover uma formação profissional embasada na aproximação dos conhecimentos específicos da Educação Física com os da escola, direcionando a atuação dos profissionais da área para o contexto do ensino formal sem abandonar as peculiaridades dessa disciplina.

Para finalizar, sugerimos a realização de novos estudos e, ainda, a discussão de outras temáticas a partir do posicionamento dos quatro grupos que fizeram parte dessa pesquisa com intuito de identificar os seus interesses e as suas projeções acerca das finalidades da formação em Educação Física.

\section{REFERÊNCIAS}

ANDRADE, Maria Margarida de. Introdução a metodologia do trabalho cientifico. 7 ed. São Paulo: Atlas S.A, 2006.

AYOUB, Eliana. Reflexões sobre a Educação Física na Educação Infantil. Revista Paulista de Educação Física, São Paulo, v. 15, supl. 4, p. 53-60, 2001.

BOURDIEU, Pierre. Sociologia. Organizado por Renato Ortiz. Tradução de Paula Montero e Alícia Auzmendi. São Paulo: Ática, 1983.

BRASIL. Conselho Nacional de Educação. Resolução n. ${ }^{\circ} \mathbf{2}$ de $\mathbf{1}^{\circ}$ de julho de 2015. Define as Diretrizes Curriculares Nacionais para a formação inicial em nível superior (cursos de licenciatura, cursos de formação pedagógica para graduados e cursos de segunda licenciatura) e para a formação continuada. Brasília/DF, 2015. 
BRASIL. Conselho Nacional de Educação. Resolução CNE/CES n. ${ }^{0} 7$ de 31 de março de 2004. Institui as Diretrizes Curriculares Nacionais para os cursos de graduação em Educação Física, em nível superior de graduação plena. Brasília/DF, 2004.

BRASIL. Conselho Nacional de Educação. Resolução CNE/CP n. 1 de 18 de fevereiro de 2002. Institui Diretrizes Curriculares Nacionais para a Formação de Professores da Educação Básica, em nível superior, curso de licenciatura, de graduação plena. Brasília/DF, 2002a.

BRASIL. Conselho Nacional de Educação. Resolução CNE/CP n. 2 de 19 de fevereiro de 2002. Institui a duração e a carga horária dos cursos de licenciatura, de graduação plena, de formação de professores da Educação Básica em nível superior. Brasília/DF, 2002b.

BRASIL. Presidência da República. Lei n. ${ }^{\circ} 9.696$ de 1 de setembro de 1998. Dispõe sobre a regulamentação da Profissão de Educação Física e cria os respectivos Conselho Federal e Conselhos Regionais de Educação Física. Brasília/DF, 1998.

CAMPOS, Luiz Antonio Silva. Os caminhos e os descaminhos da Educação Física Escolar: refletindo sobre o pensamento teórico a partir da prática docente. 2004. 164p. Tese (Doutorado em Educação Física) Universidade Estadual de Campinas, Faculdade de Educação Física, Campinas, SP. Disponível em: http://www.repositorio.unicamp.br/handle/REPOSIP/274990. Acesso em: 03 ago. 2019

CORREIA, Walter Roberto. Educação Física Escolar: o currículo como oportunidade histórica. Revista Brasileira de Educação Física e Esporte, São Paulo, v. 30, n. 3, p. 831-836, 2016.

COSTA, Luciane Cristina Arantes da; NASCIMENTO, Juarez Vieira do. O ensino da técnica e da tática: novas abordagens metodológicas. Revista de Educação Física, v. 15, n. 2, p. 49-56, 2004.

DRIGO, Alexandre Janotta; SILVA, Luiz Henrique da; FERREIRA, Heidi Jancer; SILVA, Cláudio Silvério da; SOUZA NETO, Samuel de. The socio-political scene and Henry's crisis influence on the curricula of physical education undergraduate courses in Brazil. Journal of Physical Education, v. 31, n. 1, p. 1-13, 2020 .

GALLARDO, Jorge Sergio Pérez. Delimitando os conteúdos da cultura corporal que correspondem à área de Educação Física. Conexões, Campinas/SP, v. 1, n. 1, p. 39-54, 2003.

GIL, Antônio Carlos. Métodos e técnicas de pesquisa social. 6 $6^{\text {a }}$ ed. São Paulo: Atlas, 2008.

GRAMORELLI, Lilian Cristina. A Cultura Corporal nas Propostas Curriculares Estaduais de

Educação Física: novas paisagens para um novo tempo. 2014. 189p. Tese (Doutorado em Educação) Faculdade de Educação da Universidade de São Paulo, São Paulo, 2014.

HONORATO, Ilma Célia Ribeiro. As representações sociais dos acadêmicos do curso de licenciatura em Educação Física sobre o que é ser professor. 2017. 182f. Tese (Doutorado em Educação) - Universidade Estadual de Ponta Grossa, Ponta Grossa/PR, 2017.

MAINARDES, Jefferson; MARCONDES, Maria Inês. Entrevista com Stephen J. Ball: um diálogo sobre justiça social, pesquisa e política educacional. Educação e Sociedade, Campinas/SP, v. 30, n. 106, p. 303$318,2009$.

MATTOS, Mauro Gomes de; ROSSETO JÚNIOR, Adriano José; BLECHER, Shelly. Teoria e Prática da Metodologia da Pesquisa em Educação Física: construindo sua monografia, artigo e projeto de ação. São Paulo: Phorte Editora, 2004. 
MINAYO, Maria Cecília de Souza. O desafio da pesquisa social. In: MINAYO, Maria Cecília de Souza (Org); DESLANDES, Suely Ferreira; GOMES, Romeu. Pesquisa Social: teoria, método e criatividade. $28^{\mathrm{a}}$ ed. Petrópolis, RJ: Vozes, 2009. p. 09-29.

MINAYO, Maria Cecília de Souza. O desafio do conhecimento: pesquisa qualitativa em saúde. São Paulo: Hucitec, 1993.

MOURA, Diego Luz; ANTUNES, Marcelo Moreira. Aprendizagem técnica, avaliação e Educação Física escolar. Pensar a Prática, Goiânia, v. 17, n. 3, p. 835-848, 2014.

NEIRA, Marcos Garcia; GRAMORELLI, Lilian Cristina. Embates em torno do conceito de cultura corporal: gênese e transformações. In: XIX CONBRACE - Congresso Brasileiro de Ciências do Esporte, p. 1-15, 2015, Vitória-ES. Anais eletrônicos... Disponível em: http://congressos.cbce.org.br/index.php/conbrace2015/6conice/schedConf/presentations?searchField=1\&sear chMatch=contains\&search=NEIRA\&track=288. Acesso em: 05 mai. 2019.

NEIRA, Marcos Garcia; NUNES, Mário Luiz Ferrari. Pedagogia da Cultura Corporal: crítica e alternativas. São Paulo: Phorte, 2006.

NOGUEIRA, Maria Alice; NOGUEIRA, Cláudio Martins. Bourdieu \& a Educação. $4^{\mathrm{a}}$ ed. Belo Horizonte: Autêntica Editora, 2017.

NÚÑEZ, Isauro Beltrán; RAMALHO, Betania Leite. A formação continuada dos professores que ensinam ciências naturais: pressupostos e estratégias. In: JÓFILI, Zélia; ALMEIDA, Argus Vasconcelos de (Orgs). Ensino de Biologia, meio ambiente e cidadania: olhares que se cruzam. Recife: Editora da UFRPE, 2009. p. 207-231.

OLIVEIRA, Marcus Vinícius de Faria. Pensamento teórico e formação docente: apropriação de saberes da tradição lúdica na perspectiva da teoria da formação das ações mentais por etapas de P. Ya. Galperin. 2011. 266f. Tese (Doutorado em Educação) - Universidade Federal do Rio Grande do Norte, Natal/RN, 2011.

SALGADO, Simone da Silva. Gestão e Educação Física escolar: uma mudança de postura para uma mudança de cultura. Temas em Educação Física Escolar, Rio de Janeiro, v. 2, n. 1, p. 49-69, 2017.

SAVIANI, Demerval. Sobre a natureza e especificidade da educação. Germinal: Marxismo e Educação em Debate, Salvador, v. 7, n. 1, p. 286-293, 2015.

SOUZA JÚNIOR, Marcílio; BARBOZA, Roberta de Granville; LORENZINI, Ana Rita; GUIMARÃES, Gina; SAYONE, Hilda; FERREIRA, Rita Claudia. Coletivo de Autores: a cultura corporal em questão.

Revista Brasileira de Ciências do Esporte, Florianópolis, v. 33, n. 2, p. 391-411, 2011.

TAFFAREL, Celi Nelza Zülke; LACKS, Solange; SANTOS JÚNIOR, Claudio de Lira; CARVALHO, Marise; D'AGOSTINI, Adriana; TITTON, Mauro; CASAGRANDE, Nair. Formação de professores de Educação Física para a cidade e o campo. Pensar a Prática, v. 9, n. 2, p. 153-179, 2006.

THOMAS, Jerry; NELSON, Jack. Research methods in physical activity. 3.ed. Champaign: Human Kinetics, 1996.

\section{NOTAS DE AUTOR}

AGRADECIMENTOS - Aos participantes da pesquisa.

CONTRIBUIÇÃO DE AUTORIA - Não se aplica. 


\section{FINANCIAMENTO}

Estudo realizado com apoio financeiro da Coordenação de Aperfeiçoamento de Pessoal de Nível Superior - Brasil (CAPES) - Código de Financiamento 001.

CONSENTIMENTO DE USO DE IMAGEM - Não se aplica.

\section{APROVAÇÃO DE COMITÊ DE ÉTICA EM PESQUISA}

A pesquisa obteve aprovação do Comitê de Ética em Pesquisa do Instituto de Biociências de Rio Claro/Universidade Estadual Paulista (UNESP) por meio do Parecer n. ${ }^{\circ}$ 1.658.702 (CAAE: 56771116.5.0000.5465) de 02 de Agosto de 2016.

CONFLITO DE INTERESSES - Não há conflito de interesses.

\section{LICENÇA DE USO}

Os autores cedem à Motrivivência - ISSN 2175-8042 os direitos exclusivos de primeira publicação, com o trabalho simultaneamente licenciado sob a Licença Creative Commons Attribution Non-Comercial ShareAlike (CC BY-NC SA) 4.0 International. Esta licença permite que terceiros remixem, adaptem e criem a partir do trabalho publicado, desde que para fins não comerciais, atribuindo o devido crédito de autoria e publicação inicial neste periódico desde que adotem a mesma licença, compartilhar igual. Os autores têm autorização para assumir contratos adicionais separadamente, para distribuição não exclusiva da versão do trabalho publicada neste periódico (ex.: publicar em repositório institucional, em site pessoal, publicar uma tradução, ou como capítulo de livro), com reconhecimento de autoria e publicação inicial neste periódico, desde que para fins não comerciais e compartilhar com a mesma licença.

\section{PUBLISHER}

Universidade Federal de Santa Catarina. Programa de Pós-Graduação em Educação Física. LaboMídia Laboratório e Observatório da Mídia Esportiva. Publicado no Portal de Periódicos UFSC. As ideias expressadas neste artigo são de responsabilidade de seus autores, não representando, necessariamente, a opinião dos editores ou da universidade.

\section{EDITORES}

Mauricio Roberto da Silva, Giovani De Lorenzi Pires, Rogério Santos Pereira.

\section{EDITOR DE SEÇÃO}

Juliano Silveira

\section{REVISÃO DO MANUSCRITO E METADADOS}

João Caetano Prates Rocha; Keli Barreto Santos.

\section{HISTÓRICO}

Recebido em: 07 de setembro de 2020.

Aprovado em: 04 de novembro de 2020. 